\title{
Evaluating a pilot process for reviewing late HIV diagnoses in England and Wales
}

\author{
Authors: Ming Jie Lee, ${ }^{A}$ Hilary Curtis, ${ }^{B}$ Clare van Halsema ${ }^{C}$ and David R Chadwick ${ }^{D}$
}

Late HIV diagnosis is associated with significant mortality in people living with HIV (PLWH) and high numbers of missed opportunities (MO) for earlier testing have been identified. A pilot of a national late diagnosis review process (LDRP) was undertaken in 15 HIV services evaluating the feasibility of LDRP implementation, as a patient safety initiative. All newly diagnosed PLWH with CD4 counts $<200$ cells $/ \mathrm{mm}^{3}$ were included, and healthcare episodes within 5 years of presentation reviewed. Of 127 patients identified, 40 (31.5\%) had MO and were more often white, UK-born and suffered more serious harm around diagnosis. Of these, four were designated serious incidents (undergoing root cause analysis) and eight were serious learning events. Engagement with services where MO occurred was challenging, however $75 \%$ of services found the LDRP sustainable. Widespread implementation of the LDRP should enable progress with training and policy changes within external services, enabling earlier HIV diagnosis and preventing deaths.

KEYWORDS: HIV, testing, late HIV diagnosis, missed opportunities, AIDS

DOI: 10.7861/clinmed.2019-0183

\section{Introduction}

Late HIV diagnosis is the most important predictor of morbidity and premature mortality in people diagnosed with HIV. ${ }^{1}$ In 2017 , of 4,363 people newly diagnosed with HIV in the UK, 1,879 (43\%) were diagnosed late (CD4 cell count $<350$ cells $/ \mathrm{mm}^{3}$ ), with 230 presenting with acquired immune deficiency syndrome (AIDS) defining conditions at diagnosis and 428 deaths in this period; the highest proportion being in heterosexual men (59\%) and women $(50 \%){ }^{2}$ As effective antiretroviral therapy (ART) is now available to all people living with HIV (PLWH) in the UK, a substantial proportion of these HIV-related deaths were preventable through

Authors: ${ }^{A}$ specialist registrar in genitourinary medicine and HIV, Guy's and St Thomas Hospital NHS Foundation Trust, London, UK; ${ }^{B}$ audit coordinator, British HIV Association, Letchworth, UK; ${ }^{C}$ consultant physician in infectious diseases, North Manchester General Hospital, Manchester, UK; ${ }^{D}$ consultant physician in infectious diseases, South Tees Hospitals NHS Foundation Trust, Middlesbrough, UK earlier detection, linkage to care and treatment. ${ }^{3}$ An additional benefit of earlier diagnosis in PLWH is that ART prevents transmission of HIV to sexual partners. A UK national audit in 2016 revealed $46 \%$ of 773 patients with very late HIV diagnoses (CD4 count $<200$ cells $/ \mathrm{mm}^{3}$ ) had missed opportunities (MO) for HIV testing in the years prior to diagnosis. ${ }^{4}$ The majority of $\mathrm{MO}$ were presentations with clinical indicator conditions for HIV testing where a test was not done, and common presentations include blood dyscrasias, weight loss and lymphadenopathy. ${ }^{5-7}$ Tables $1 \mathrm{a}$ and $1 \mathrm{~b}$ summarise clinical indicator diseases, and settings or risk factors where HIV testing is recommended by the UK national guidelines for HIV testing, however these are currently under revision and updated national guidelines are due to be released for consultation at time of writing; Table $1 \mathrm{~b}$ has been adapted to reflect some of the likely recommendations in the new guidelines. ${ }^{5}$

British HIV Association (BHIVA) Standards of Care recommend HIV services undertake a review of all patients diagnosed late, and 'look back' at previous health care engagement to aid greater understanding of interventions to reduce late diagnosis. ${ }^{8}$ However, $55 \%$ of HIV services in the UK national audit in 2016 had not undertaken an organised 'look back' review of late diagnoses. Reasons for not doing so appear to be a lack of clearly defined national 'look back' process, lack of good access to health record data, concerns about stigma, embarrassment or confidentiality, and concerns about apportioning blame. ${ }^{9}$ Even when $\mathrm{MO}$ are identified, $33.8 \%$ did not lead to follow-up interventions or feedback to the relevant services. ${ }^{4}$

In April 2018, as a patient safety initiative, the NHS England HIV Clinical Reference Group and BHIVA approved a national late diagnosis review process (LDRP) to evaluate the feasibility of a retrospective case review for very late HIV diagnoses in a multisite pilot across England and Wales. ${ }^{9}$

\section{Methods}

Patients and eligibility

Fifteen HIV services across England and Wales participated in the LDRP pilot, which was carried out between July and December 2018. Approval for the process was sought from local patient safety departments as a quality improvement project. The eligibility criteria and pathway are shown in Fig 1. All new patients presenting to each HIV service with a very late diagnosis (CD4 count $<200$ cells $/ \mathrm{mm}^{3}$ ), and resident in the UK for at least 2 months were included. A 'look back' period of 5 years was undertaken. 


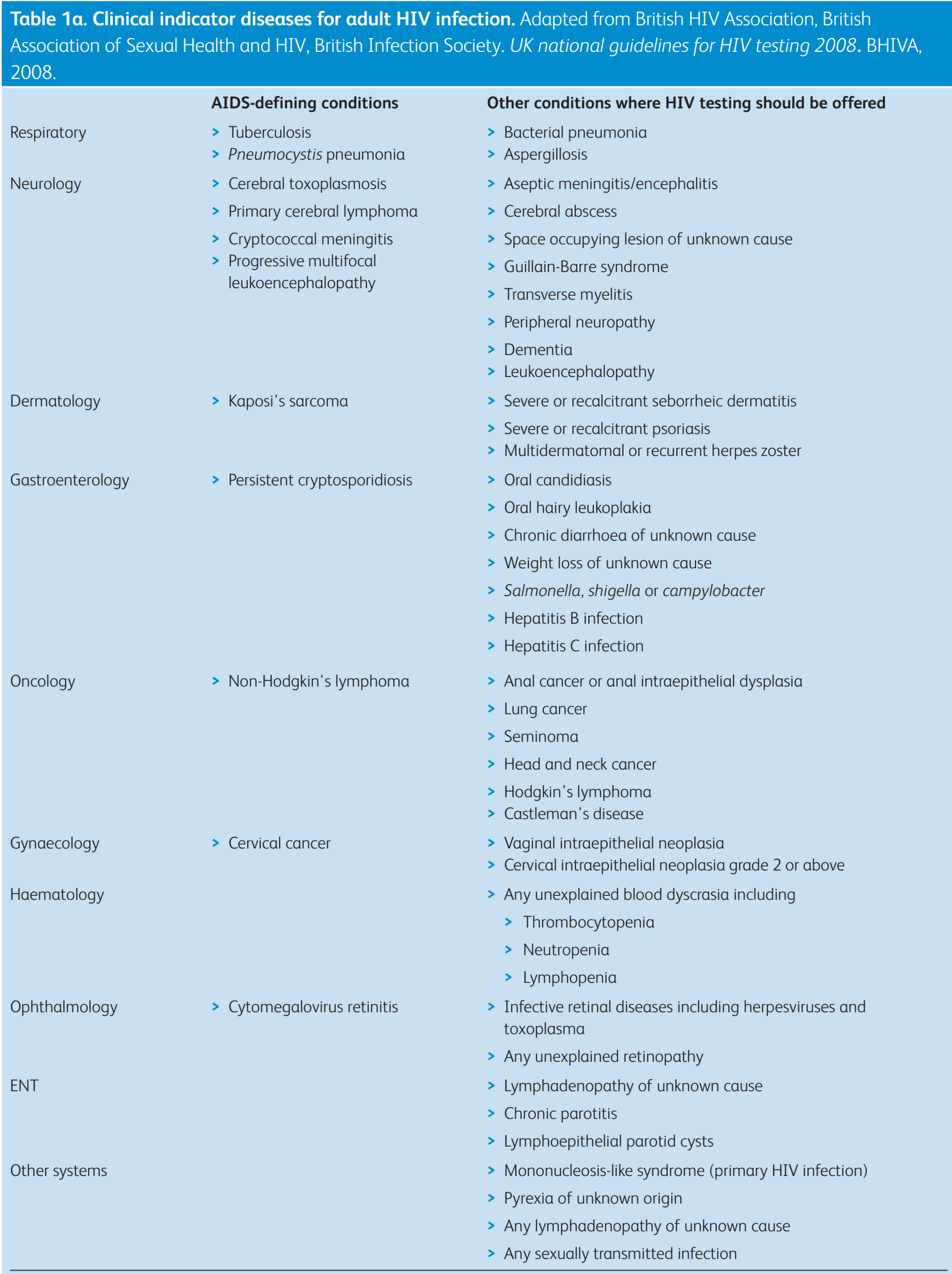

AIDS = acquired immune deficiency syndrome. 
Table 1b. Who should be offered a test? Adapted from British HIV Association, British Association of Sexual Health and HIV, British Infection Society. UK national guidelines for HIV testing 2008. BHIVA, 2008.

\begin{tabular}{|c|c|}
\hline Universal HIV testing is recommended in: & $\begin{aligned}> & \text { genitourinary medicine or sexual health clinics } \\
> & \text { antenatal services } \\
> & \text { termination of pregnancy services } \\
> & \text { drug dependency programmes } \\
> & \text { healthcare services for those diagnosed with tuberculosis, } \\
& \text { hepatitis } B \text {, hepatitis } C \text { and lymphoma. }\end{aligned}$ \\
\hline $\begin{array}{l}\text { Routine HIV testing is recommended in the } \\
\text { following settings, where diagnosed HIV prevalence } \\
\text { in the local population exceeds } 2 / 1,000 \text { : }\end{array}$ & $\begin{array}{l}\text { > all men and women registering in general practice } \\
>\text { all general medical admissions. }\end{array}$ \\
\hline $\begin{array}{l}\text { HIV testing should also be routinely offered } \\
\text { and recommended for: }\end{array}$ & $\begin{aligned} & \text { > } \text { all patients presenting for healthcare where HIV, including } \\
& \text { primary HIV infection, enters the differential diagnoses } \\
&>\text { all patients diagnosed with a sexually transmitted infection } \\
&>\text { all sexual partners of men and women known to be HIV } \\
& \text { positive } \\
&>\text { all men who have disclosed sexual contact with other men } \\
&>\text { all female sexual contacts of men who have sex with men } \\
&>\text { all transgender persons } \\
&>\text { all patients reporting a history of injecting drug use } \\
&>\text { all men and women known to be from a country of high HIV } \\
& \text { prevalence }(>1 \%)^{a} \\
&>\text { all men and women who report sexual contact abroad or in } \\
& \text { the UK with individuals from countries of high prevalence. }\end{aligned}$ \\
\hline
\end{tabular}

\section{Review process}

Patient notes (paper or electronic), pathology systems, general practice (GP) summary care records (SCR) and other electronic record systems were reviewed up to 5 years prior to diagnosis by an experienced clinician within the HIV service. Patient recall of any other healthcare episodes not documented above was also included. Each healthcare episode where a MO for HIV testing was identified was classed as 'possible' or 'definite'. MO were defined as 'definite' if patients presented to any healthcare service with a HIV clinical indicator disease or risk factor for infection, according to national testing guidelines (Table 1a), and did not undertake HIV testing, or 'possible' if the presenting complaint did not meet the 'definite' criteria but were considered likely to HIV-related.

Patient harm was graded according to a modified NHS improvement grading system (Fig 2a). ${ }^{10}$ If significant harm (grade 2 or above) had occurred, was judged to be preventable via earlier diagnosis and coupled with definite $\mathrm{MO}$ for earlier testing, a serious incident (SI) or serious learning event (SLE) review was triggered (Fig 2b). An SI investigation included root cause analysis (RCA), which may also be included in a serious learning event according to the organisation's protocols. If there were possible $\mathrm{MO}$ and no or minimal harm, then feedback to the external services where the MO occurred was provided by letter. The RCA and SLE processes were carried out in accordance with local services governance pathways and in liaison with their patient safety teams. Services were encouraged to report deaths associated with SI reports to the local coroner.

\section{Evaluation of pilot}

Details of patient demographics, MO to test and harm suffered were collected and analysed. After the pilot period, all HIV services involved were asked to complete an online structured survey. Questions covered four domains: identifying MO, feedback to external services where $\mathrm{MO}$ occurred, outcomes from the RCA and SLE process, and overall feedback from individual HIV services on the LDRP. There was also a free text section for comments on the process and services were encouraged to provide details of how any deaths were investigated internally as well as through the coroner. For statistical analysis, Pearson's $\chi^{2}$ test or Student's t-test was used for categorical and continuous variables for univariate analysis, respectively, using the statistical package Minitab (Coventry, UK).

\section{Results}

\section{Population characteristics}

One-hundred and twenty-seven very late diagnoses were identified during the LDRP pilot, 40 (31.5\%) who had 79 possible or definite MO identified for earlier testing: 30 (38\%) were defined as definite MO. Forty-five (57\%) took place in a general practice setting, seven $(8.9 \%)$ in emergency departments or inpatient admissions. Clinical indicator conditions were present in $58.2 \%$ of $\mathrm{MO}$ (Table 2). Very late diagnoses with $\mathrm{MO}$ were more likely to be white $(70.0 \%$ vs $47.1 \%$; $p=0.016)$, and UK-born ( $57.5 \%$ vs $29.9 \% ; p=0.003)$. There were no differences in age, gender and likely route of HIV acquisition between those with $\mathrm{MO}$ or without. Patients with MO had lower CD4-counts and AIDS-defining conditions at diagnosis (Table 3). 


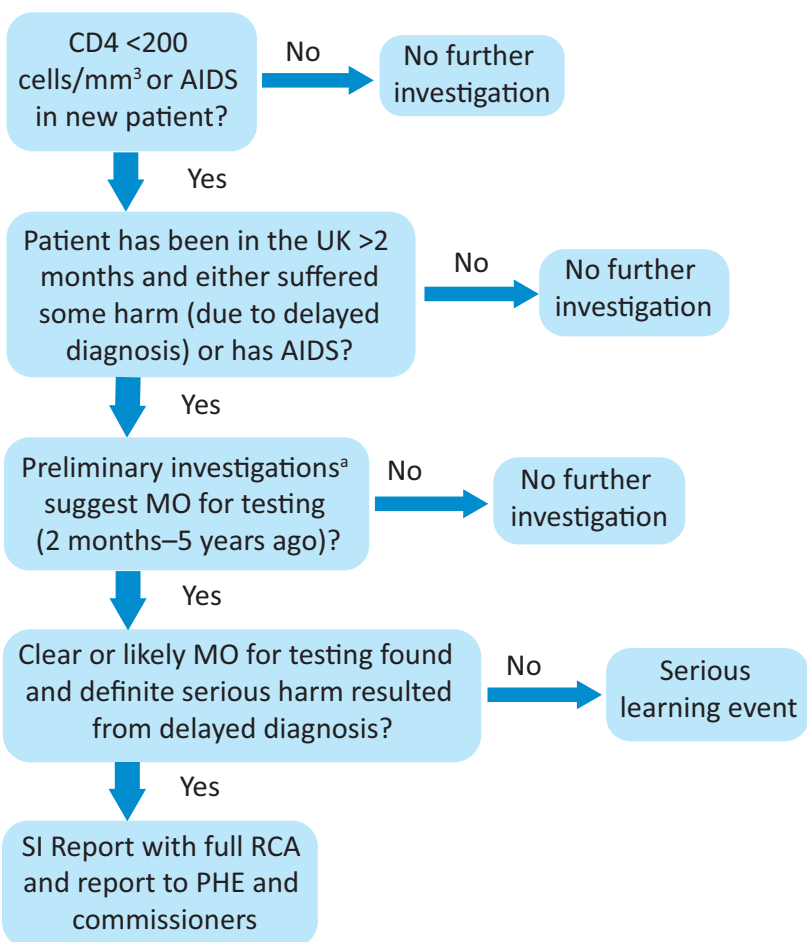

Fig 1. Late diagnosis process eligibility criteria and pathway.

${ }^{a}=$ from medical notes, other electronic records (eg NHS Spine or Path data) and patient history; AIDS = acquired immune deficiency syndrome; $\mathrm{MO}$ $=$ missed opportunities; PHE = Public Health England; RCA = root cause analysis; SI = serious incident.

\section{Patient safety reviews}

Few MO episodes $(9 / 68 ; 13 \%)$ were reviewed with the full range of tools (notes, pathology system, SCR and patient recall) and most patients could only be reviewed with two modalities. Patients with $\mathrm{MO}$ were more likely to experience grade 3 (moderate) or worse harm, than no or mild harm ( $72.5 \%$ vs $37.9 \%$; $p<0.0001)$. Two deaths $(5.0 \%)$ were reported in those with $\mathrm{MO}$, compared with one death $(1.1 \%)$ in those without. Following case reviews, a letter was sent to the relevant service in 15 cases, a SLE conducted in eight cases, and there were four SIs requiring RCAs to be undertaken. Data on the outcomes of SI/SLE reviews were incomplete, however, it appears that, in most cases, engagement of services outside the organisation reporting the SI/SLE was poor. Where there was engagement from services where MO had occurred, useful learning and policy changes to promote HIV testing resulted. In cases where letters were sent (without SI/SLE) informing services of $\mathrm{MO}$ to test, very few responses were received by the services participating in the evaluation survey.

\section{Site survey responses}

All 15 participating services completed the evaluation survey. Nine services $(60 \%)$ sought verbal consent to carry out the LDRP where possible, while the remaining services carried out the identification of $\mathrm{MO}$ in the patient's best interest. Nine patients declined consent when asked and, in a further two cases reported by the services, it was not feasible to obtain consent due to one patient being uncontactable and another who died prior to obtaining consent.
Of the ten services reported in the survey requiring RCAs or SLEs, an incident report (eg DATIX) was logged in four cases, but in three services the external services (where the MO had occurred) were asked to log the incident. In a further three cases, alternative patient safety management processes took place not requiring an incident report. Eleven of 13 services identifying $\mathrm{MO}$ contacted the external services to initiate a serious incident process, one service was awaiting the outcome of the SLE/RCA process to the finalised before contacting and, in the remaining case, the LDRP was being undertaken by a separate HIV service. Of the eleven services who contacted external services, only one (10\%) reported a response with engagement in the feedback process to enable earlier testing. Eleven services $(73.3 \%$ ) agreed the LDRP was a sustainable process in their departments, with 11 (91.7\%) reporting spending less than 2 hours a week on the LDRP. Support from specialist nurses (33\%), health advisors (13.3\%) and other administrative staff $(6.7 \%)$ for the LDRP was also evident in many services. Various free-text comments identified a number of logistic challenges with the LDRP, however most services were very much in favour of the process, and many already had HIV late diagnosis case discussions alongside regular department or mortality meetings. One challenge frequently identified was when multiple organisations were involved, with debate around which organisation should to take responsibility for coordinating the investigation process.

\section{Management of HIV-related deaths}

Two of the three deaths recorded triggered an SI report (and $\mathrm{RCA}$ ), since the previous $\mathrm{MO}$ to test for HIV were considered to constitute avoidable harm. However, neither of these deaths had yet been reported to the coroner. Although just outside the pilot period, one service reported three coroner's referrals for HIV-related deaths where, in each case, multiple MO were apparent in different medical outpatient specialties, including haematology, respiratory medicine and gastroenterology, with unnecessary investigations including radiology, endoscopy and tissue biopsies. There was evidence not only of MO to test when patients presented with indicator conditions, but also lack of consideration of HIV as part of a differential diagnosis. Organisational learning from RCAs, before coroners' hearings have taken place, led to the establishment of a 'task and finish' group to implement universal HIV testing in the organisation. Recommendations on HIV testing in outpatient settings are noted to be absent from the National Institute for Health and Care Excellence (NICE) 2016 guidance on testing and this will be considered in the planned roll-out of HIV testing in this centre in view of the nature of $\mathrm{MO}$ occurring locally. ${ }^{11}$ It is hoped that patient safety processes related to these deaths recorded during the pilot period will stimulate further efforts locally to improve compliance with HIV testing guidelines.

\section{Discussion}

\section{Effectiveness of the pilot process}

The national LDRP pilot provides the first national systematic case review process for identifying $\mathrm{MO}$ for earlier HIV testing in very late diagnoses and harm resulting from delayed diagnosis, which is both clearly defined and utilises existing patient safety procedures. Data from this pilot scheme showed that, compared with a national audit between 2015 to $2016,{ }^{4}$ the proportion of very late diagnoses with $\mathrm{MO}$ for earlier testing was lower 
a

\begin{tabular}{|c|c|c|}
\hline Score & 1 & 2 \\
\hline Domains & Negligible & Minor \\
\hline $\begin{array}{l}\text { Impact of the } \\
\text { safety of patients, } \\
\text { staff or public } \\
\text { (physical/ } \\
\text { psychological harm) }\end{array}$ & $\begin{array}{l}\text { Minimal injury } \\
\text { requiring no/ } \\
\text { minimal intervention } \\
\text { or treatment. } \\
\text { No time off work } \\
\text { required. }\end{array}$ & $\begin{array}{l}\text { Minor injury or } \\
\text { illness requiring } \\
\text { minor intervention. } \\
\text { Requiring }<3 \text { days } \\
\text { off work. Increase } \\
\text { in LOS by } 1-3 \text { days. }\end{array}$ \\
\hline
\end{tabular}

\begin{tabular}{|c|c|c|}
\hline 3 & 4 & 5 \\
\hline Moderate & Major & Catastrophic \\
\hline $\begin{array}{l}\text { Moderate injury } \\
\text { requiring professional } \\
\text { intervention. Requiring } \\
\text { 4-14 days off work. } \\
\text { Increase in LOS by } \\
4-15 \text { days. RIDDOR/ } \\
\text { agency reportable } \\
\text { incident. An event } \\
\text { which impacts on } \\
\text { a small number } \\
\text { of patients. }\end{array}$ & $\begin{array}{l}\text { Major injury leading } \\
\text { to long-term incapacity/ } \\
\text { disability. Requiring } \\
>14 \text { days off work. } \\
\text { Increase in LOS } \\
\text { by }>15 \text { days. } \\
\text { Mismanagement of } \\
\text { patient care with } \\
\text { long-term effects. }\end{array}$ & $\begin{array}{l}\text { Incident leading } \\
\text { to death. Multiple } \\
\text { permanent injuries } \\
\text { or irreversible } \\
\text { health effects. } \\
\text { An event which } \\
\text { impacts on a large } \\
\text { number of patients. }\end{array}$ \\
\hline
\end{tabular}

b
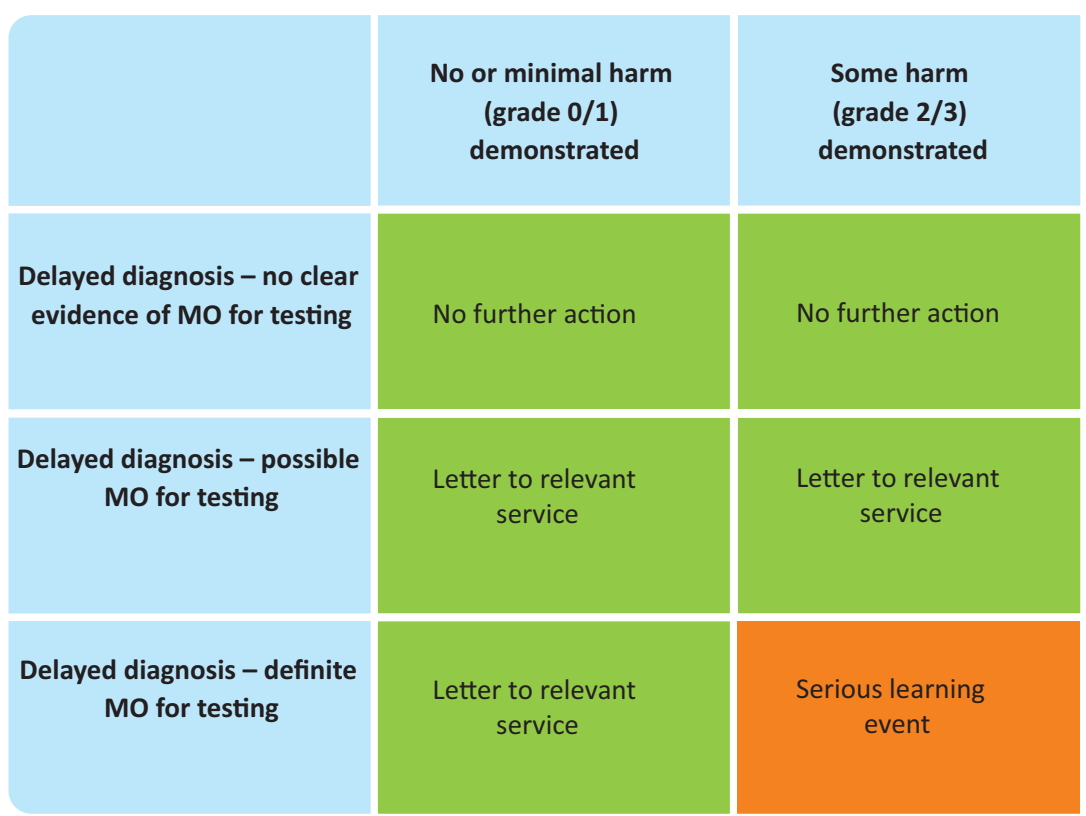

\section{Serious harm \\ (grade 4/5) \\ demonstrated}
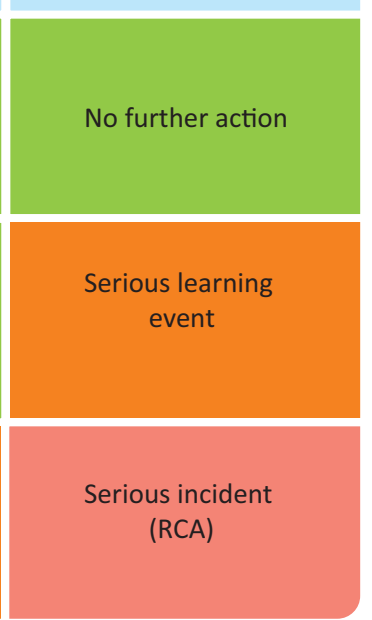

Fig 2. a) Harm grading system, consequence score (severity levels) and examples of descriptors. ${ }^{10}$ b) Outcome processes for late diagnoses. LOS $=$ length of hospital stay; MO = missed opportunities; RCA = root cause analysis; RIDDOR = Reporting of Injuries, Diseases and Dangerous Occurrences Regulations.

(46.2\% vs $31.5 \%$ ), although this may have been because many of the participating centres had limited tools for reviewing healthcare episodes outside their organisations. As seen in previous studies, most MO occurred in general practice, which illustrates that many clinicians in primary care remain unfamiliar with testing guidelines, and interventions to support HIV testing in this setting are needed. A systematic review of barriers to HIV testing in primary care settings in Europe identified a lack of familiarity with testing guidelines and issues of communication about sexual health. ${ }^{12}$ Other studies have also raised the following concerns in primary care: lack of time to conduct HIV tests, mischaracterisation of pretest counselling as complex and time-consuming, concerns around result management and the belief that HIV test results were best delivered by staff with specialised training. ${ }^{13,14}$ However, there is evidence that provision of specific training, practical tools or an HIV testing promotion programme may improve HIV testing rates in general practice, particularly in areas of high prevalence. ${ }^{15-18}$

In this pilot, PLWH for whom MO were identified were more likely to be white, and UK-born, consistent with other studies suggesting that individuals born in high-income countries may be inaccurately presumed to be low risk for HIV by healthcare providers when they present without apparent risk factors. ${ }^{19,20}$ Data on the nature of $\mathrm{MO}$ were not specifically collected, however the most common indicator conditions identified were mononucleosis-like illness, recurrent leukopenia or thrombocytopenia, recurrent shingles, candidiasis, lymphadenopathy and weight loss. Specific training programmes to increase HIV testing awareness should address this misconception, particularly in high prevalence regions. There remain challenges in implementation of a national LDRP. Only one HIV service reported positive engagement from external services when feedback about the MO for HIV testing was given, the remaining HIV services reporting a lack of response or engagement from the external services. The situation remains unchanged from that previously described in the 2015-2016 national audit where only 13\% of respondents were aware of changes in HIV testing practice arising from learning based on MO. ${ }^{4}$ Perhaps more worrying, external services' engagement with SI and SLE investigating processes were poor and highlights the need for patient safety teams to engage with other organisations' patient safety teams, and for service commissioners to emphasise the importance of expanded HIV testing strategies. At least one centre 


\begin{tabular}{|c|c|c|}
\hline & $n$, total $n=79$ & $\%$ \\
\hline \multicolumn{3}{|l|}{ Definition of MO episode } \\
\hline Definite MO & 30 & 38.0 \\
\hline Possible MO & 49 & 62.0 \\
\hline \multicolumn{3}{|l|}{ Location of MO episode } \\
\hline General practice & 45 & 57.0 \\
\hline $\begin{array}{l}\text { Emergency department or inpatient } \\
\text { admission }\end{array}$ & 7 & 8.9 \\
\hline Other settings & 27 & 34.2 \\
\hline \multicolumn{3}{|l|}{$\begin{array}{l}\text { Reason HIV test should have been } \\
\text { offered }\end{array}$} \\
\hline Indicator condition & 46 & 58.2 \\
\hline $\begin{array}{l}\text { Originated from high prevalence } \\
\text { country }\end{array}$ & 9 & 11.4 \\
\hline High-risk sexual partner & 2 & 2.5 \\
\hline Other reasons & 22 & 27.9 \\
\hline
\end{tabular}

reported that raising an SI/SLE report through their patient safety team was a more effective method of feedback than previously used methods. This highlights the importance of local HIV services and patient safety teams working together to create a feedback pathway and reduce $\mathrm{MO}$ for $\mathrm{HIV}$ testing.

Although some centres reported concerns of increased workload, feedback from the evaluation survey suggests the LDRP is a sustainable process with current resources. Another concern was whether the process required patient consent. While $40 \%$ of the centres proceeded with the LDRP in the patients' best interests, $60 \%$ of centres were advised to obtain consent of the patient prior to conducting the LDRP, and this was not successful in 11 cases. It is our view that, in accordance with the NHS Serious Incident Framework openness and transparency principle, patients should be informed of a serious incident and the subsequent investigation, but that their consent is not needed. ${ }^{21}$ However, clarity is needed regarding cases not requiring an SI.

\section{Late HIV diagnosis as a patient safety issue}

The concept of treating late HIV diagnoses as a patient safety issue has recently been raised, where clear $\mathrm{MO}$ to test are evident and significant avoidable harm results. ${ }^{22}$ There is a strong argument that, in such cases, failure to test for HIV according to national guidelines, and subsequent resulting harm, constitutes diagnostic error and fulfils the criteria for omissions in care. Hence processes

Table 3. Demographics and HIV clinical markers at diagnosis in very late diagnoses

\begin{tabular}{|c|c|c|c|}
\hline & $\begin{array}{l}\text { Very late diagnoses without } \\
\text { missed opportunity, total } n=87\end{array}$ & $\begin{array}{l}\text { Very late diagnoses with missed } \\
\text { opportunity, total } n=40\end{array}$ & $\mathrm{p}$ value \\
\hline Mean $\pm S D$ age, years & $44.1 \pm 12.1$ & $46.9 \pm 12.6$ & 0.238 \\
\hline \multicolumn{4}{|l|}{ Gender } \\
\hline Male, $\mathrm{n}(\%)$ & $60(69.0)$ & $31(77.5)$ & \multirow[t]{3}{*}{0.367} \\
\hline Female, $n(\%)$ & $26(29.9)$ & $9(22.5)$ & \\
\hline Transgender, $\mathrm{n}(\%)$ & $1(1.1)$ & $0(0.0)$ & \\
\hline \multicolumn{4}{|l|}{ Route of HIV transmission } \\
\hline Heterosexual, n (\%) & $60(69.0)$ & $24(60.0)$ & \multirow[t]{3}{*}{0.240} \\
\hline MSM, n (\%) & $25(28.7)$ & $16(40.0)$ & \\
\hline Other, $\mathrm{n}(\%)$ & $2(2.3)$ & $0(0.0)$ & \\
\hline \multicolumn{4}{|l|}{ Ethnicity } \\
\hline White, n (\%) & $41(47.1)$ & $28(70.0)$ & \multirow[t]{2}{*}{$0.016^{*}$} \\
\hline Non-white, n (\%) & $46(52.9)$ & $12(30.0)$ & \\
\hline \multicolumn{4}{|l|}{ Country of birth } \\
\hline UK, n (\%) & $26(29.9)$ & $23(57.5)$ & \multirow[t]{2}{*}{$0.003^{*}$} \\
\hline Outside UK, n (\%) & $61(70.1)$ & $17(42.5)$ & \\
\hline Mean $\pm S D$ CD4 count at diagnosis, cells $/ \mathrm{mm}^{3}$ & $101.4 \pm 78.2$ & $61 \pm 64.5$ & $0.003^{*}$ \\
\hline $\begin{array}{l}\text { Mean } \pm \text { SD HIV viral load at diagnosis, } \\
\text { copies } / m L\end{array}$ & $1,043,498 \pm 3,565,733$ & $733,471 \pm 1,655,354$ & 0.506 \\
\hline AIDS-defining conditions at diagnosis, $n$ (\%) & $28(32.2)$ & $26(65.0)$ & $0.001^{*}$ \\
\hline Grade 3 or worse harm, $\mathrm{n}$ (\%) & $30(34.5)$ & $29(72.5)$ & $<0.0001^{*}$ \\
\hline Deaths, n (\%) & $1(1.1)$ & $2(5.0)$ & - \\
\hline
\end{tabular}


and tools such as SI reporting with RCA have been underutilised in most cases where avoidable harm has occurred due to $\mathrm{MO}$ to test PLWH, and opportunities for learning missed. To our knowledge, very few deaths in such circumstances have previously been designated as SIs or reported to coroners. While this is perhaps understandable given the sensitivity and stigma of HIV-related deaths, and in some cases the difficulty in establishing that there were clear $\mathrm{MO}$ to test, we believe that there needs to be a change in how such deaths are reviewed to enable individual and institutional learning.

\section{Conclusion}

This study demonstrated that a retrospective case review process for patients diagnosed very late with HIV was both feasible and effective in identifying $\mathrm{MO}$ for testing and highlighting cases where harm resulted from previous failures to test for HIV. The review process was able to select appropriately patients for SI or SLE reporting. With expansion of this process to all HIV care providers across England and Wales as a commissioned specification, it is hoped that it will provide impetus to expand HIV testing and reduce rates of very late diagnosis of HIV.

\section{Acknowledgements}

We would like to thank the patients and clinical teams at each of the service involved in the LDRP, listed in supplementary material S1, and the patient safety teams at each organisation for their assistance with this process.

\section{Conflicts of interest}

Ming Jie Lee has received speaker fees from Gilead Sciences outside of the submitted work. David R Chadwick has received research funding from ViiV Healthcare and speaker fees from Gilead Sciences outside of the submitted work. Clare van Halsema has received speaker fees from Gilead Sciences, conference sponsorship from ViiV Healthcare and Merck Sharp \& Dohme, and has participated in an advisory board for ViiV Healthcare, all unrelated to the submitted work.

\section{Supplementary material}

Additional supplementary material may be found in the online version of this article at www.rcpjournals.org/content/clinmedicine: S1 - Acknowledgements and list of HIV services involved.

\section{References}

1 Chadborn TR, Delpech VC, Sabin CA, Sinka K, Evans BG. The late diagnosis and consequent short-term mortality of HIV infected heterosexuals (England and Wales, 2000-2004). AIDS 2006; 20:2371-9.

2 Public Health England. Progress towards ending the HIV epidemic in the United Kingdom: 2018 Report. London: PHE, 2018.

3 Croxford S, Kitching A, Desai S et al. Mortality and causes of death in people diagnosed with HIV in the era of highly active antiretroviral therapy compared with the general population: an analysis of a national observational cohort. Lancet Public Health 2017;2: e35-46.

4 Byrne R, Curtis $\mathrm{H}$, Sullivan A et al. A National Audit of late diagnosis of HIV: action taken to review previous healthcare among individuals with advanced HIV. British HIV Association, 2018. www. bhiva.org/NationalAuditReports [Accessed 02 October 2019].

5 British HIV Association, British Association of Sexual Health and HIV, British Infection Society. UK national guidelines for HIV testing 2008. BHIVA, 2008. www.bhiva.org/file/RHNUJgIseDaML/ GlinesHIVTest08.pdf [Accessed 02 October 2019].

6 Ellis S, Curtis H, Ong EL. HIV diagnoses and missed opportunities. Results of the British HIV Association (BHIVA) National Audit 2010. Clin Med 2012;12:430-4.

7 Tominski D, Katchanov J, Driesch D et al. The late-presenting HIVinfected patient 30 years after the introduction of HIV testing: spectrum of opportunistic diseases and Missed Opportunities for early diagnosis. HIV Med 2017;18:125-32.

8 British HIV Association. Standards of care for people living with HIV 2018. BHIVA, 2018.

9 Chadwick D. Late HIV diagnosis: Pilot review process to identify missed opportunities for testing. British HIV Association Autumn Conference 2018 - Presentations. BHIVA, 2018. www.bhiva.org/ Autumn2018Presentations [Accessed 27 April 2019].

10 NHS National reporting and learning system. Degree of harm FAQ. NHS. https://improvement.nhs.uk/documents/1673/NRLS_Degree_ of_harm_FAQs_-_final_v1.1.pdf [Accessed 09 April 2019].

11 National Institute for Health and Care Excellence. HIV testing: increasing uptake among people who may have undiagnosed HIV. NICE guideline [NG60]. NICE, 2016. www.nice.org.uk/guidance/ ng60/resources/hiv-testing-increasing-uptake-among-people-whomay-have-undiagnosed-hiv-pdf-1837567043269 [Accessed 03 June 2019].

12 Deblonde J, Van Beckhoven D, Loos ] et al. HIV testing within general practices in Europe: a mixed-methods systematic review. BMC Public Health 2018;18:1191.

13 Thornton AC, Rayment M, Elam G et al. Exploring staff attitudes to routine HIV testing in non-traditional settings: a qualitative study in four healthcare facilities. Sex Transm Infect 2012;88:601-6.

14 Manirankunda L, Loos J, Debackaere P, Noestlinger C. It is not easy: challenges for provider-initiated HIV testing and counselling in Flanders, Belgium. AIDS Educ Prev 2012;24:456-68.

15 Loos J, Manirankunda L, Hendrickx K, Remmen R, Noestlinger C. HIV testing in primary care: feasibility and acceptability of provider initiated HIV testing and counselling for sub-Saharan African migrants. AIDS Educ Prev 2014;26: 81-93.

16 Mahendran P, Soni S, Goubet $S$ et al. Testing initiatives increases rates of HIV diagnosis in primary care and community settings: an observational single-centre cohort study. PLoS One 2015; 10:e0124394

17 Pillay TD, Mullineux J, Smith C], Matthews P. Unlocking the potential: longitudinal audit finds multifaceted education for general practice increases HIV testing and diagnosis. Postgrad Med J 2014;90:86-91.

18 Sicsic ], Saint-Lary O, Rouveix E, Pelletier-Fleury N. Impact of a primary care national policy on HIV screening in France: a longitudinal analysis between 2006 and 2013. Br J Gen Pract 2016;66:e920.

19 Nanditha NGA, St-Jean M, Tafessu H et al. Missed opportunities for earlier diagnosis of HIV in British Columbia, Canada: A retrospective cohort study. PLoS One 2019;14:e0214012.

20. Youssef E, Cooper V, Delpech V, Davies K, Wright J. Barriers and facilitators to HIV testing in people age 50 and above: a systematic review. Clin Med 2017:17:508-20.

21 NHS England. Serious Incident Framework: Supporting learning to prevent recurrence. NHS, 2015. www.england.nhs.uk/wp-content/ uploads/2015/04/serious-incidnt-framwrk-upd.pdf [Accessed 28 April 2019].

22 Chadwick DR, Freedman A. Treating late HIV diagnosis as a patient safety issue in the United Kingdom. Lancet HIV 2019;6:e346-8.

Address for correspondence: Dr Ming Jie Lee, Harrison Wing, Guy's Hospital, Guy's and St Thomas' Hospital NHS Foundation Trust, Great Maze Pond, London SE1 9RT, UK.

Email: minglee@doctors.org.uk 